\title{
Understanding Soil as an Open System and Fertility as an Emergent Property of the Soil System
}

\author{
Margarete Nicolodi ${ }^{1} \&$ Clesio Gianello ${ }^{2}$ \\ ${ }^{1}$ Post-Graduate Program in Soil Science, Federal University of Rio Grande do Sul, Porto Alegre, Brazil \\ ${ }^{2}$ Soil Department, Federal University of Rio Grande do Sul, Porto Alegre, Brazil \\ Correspondence: Margarete Nicolodi, Laboratório de Analises de Solo, Faculdade de Agronomia, UFRGS, Av. \\ Bento Gonçalves, n. 7712, CEP 91540-000, Porto Alegre, RS, Brazil. E-mail: marganicolodi@hotmail.com
}

Received: November 13, 2014 Accepted: December 16, $2014 \quad$ Online Published: December 23, 2014
$\begin{aligned} & \text { doi:10.5539/sar.v4n1p94 } \\ & \text { URL: http://dx.doi.org/10.5539/sar.v4n1p94 }\end{aligned}$

\begin{abstract}
The application of the principles of thermodynamics and General Systems Theory is responsible for important progress in the study of soil and its fertility, and this application can even improve our understanding of the processes that govern the functioning of soil and determine the magnitude of soil fertility. Consequently, we can improve the evaluation and practices recommended for preserving or improving the soil and its fertility, contributing to sustainable food production. Recalling how the concept and human perception of soil have evolved is fundamental to improve our understanding. Thus, this article aims to encourage people to reflect on the application of the principles of thermodynamics of non-equilibrium and General Systems Theory in studying the soil and its fertility and to participate in constructing a new notion of soil fertility, able to express what is perceived by plants. Several authors in the last century have considered the soil to be an open system; however, this approach is a recent in Brazil. Fertility can be coherently understood as one of the emergent properties of the soil system by applying the principles of thermodynamics of non-equilibrium and General Systems Theory to the study of soil.
\end{abstract}

Keywords: thermodynamics of non-equilibrium, systems theory, new concept, function, approach

\section{Introduction}

Soil is an open system (Note 1) (Jenny, 1941), and its functioning is determined by the interaction among its subsystems (Dijkerman, 1974) and the surrounding systems. This interaction is affected by the flows that permeate it (Hugget, 1976). Consequently, it remains apart from thermodynamic equilibrium (Denbigh, 1951) and is constantly evolving (Yallon, 1975). Soil is only formed by the action of life systems on regolith or the interaction of life systems with the rock matrix and climate. In response to pedogenic action, regolith transforms in soil and becomes endowed of the ability to allow the plant development (Haussmann, 1950). This ability is called fertility, which can be defined as an emergent property (Note 2) of the soil system that provides the conditions necessary to sustain plant life (Nicolodi, 2007). In response to soil system functioning, the fertility emerges to a greater or lesser magnitude. The manner in which the magnitude of fertility is perceived by plants results in their productivity. With this conception of soil and its fertility, we seek to maximally approximate the understanding that people have and the evaluation that they perform of fertility to what the plants perceive when cultivated in soil. This purpose is especially important in that soils cultivated in no-tillage system (NTS), for which the mineralist concept is insufficient in expressing the soil fertility perceived by plants (Nicolodi et al., 2014). Even before this lack had been proven in the field, Patzel et al. (2000) emphasized the importance of rethinking the phenomenon of fertility in modern terms and discuss the concept to improve communication among researchers from diverse cultures and languages in an extensive and important review.

This article aims to encourage people to reflect on their notions regarding soil and its fertility and to participate in constructing a new notion of soil fertility, able to express what is perceived by plants. To evaluate the consistency of understanding soil fertility as an emergent property of the soil system, it is important to recall some of important observations made by scientists who have been studying soil since it was first perceived as an open system. It is also necessary to observe how soil and its fertility are approached to reflect on formation, which are the main functions of the soil system, and how fertility can be understood within this systemic approach to the soil. 


\section{Development}

\subsection{Soil, an Open System}

The perception of soil, expressed in its concept, shows that the understanding that people have regarding soil has improved with the use of classical or equilibrium thermodynamics (Note 3), but it improved notably with thermodynamics of non-equilibrium and the systemic approach.

At the end of the nineteenth century, soil was conceptualized as a mineral and organic superficial deposition, with more or less the color of humus, resulted from the mutual action of living or dead organisms (plants and animals), of climate, and of landscape (Dokuchaev, 1879). In the twentieth century, the concept of soil as a medium for plant growth prevailed (Saltini, 1984). In the 1930s, the perception of soil began changing as the use of classical thermodynamics to improve our understanding. The soil was thus understood as a natural body, unconsolidated (Joffe, 1936), dynamic, and in equilibrium with the environment (Kellogg, 1936), as well as a system whose solid-phase components are physically and chemically in dynamic equilibrium with the liquid-and gas-phase components (Camargo \& Vageler, 1938). However, an understanding of soil as an open system, to which substances can be added or removed, was first proposed by Jenny (1941). According to this author, soil is the result of the interactions among climate, organisms, landscape, rock matrix, and formation time. It is part of the many large systems comprising the upper portion of the lithosphere, the lower portion of the atmosphere, and a considerable portion of the biosphere, and substances can be added to and removed from it. Ten years later, Denbigh (1951) concluded that the concept of equilibrium in classical thermodynamics was not valid for open systems such as soil. In 1973, Runge (1973) considered the soil an open system, and Chesworth (1973) used the basis of thermodynamics of non-equilibrium to understand it.

The soil system has a very complex hierarchical organization and comprises a network of relationships (Rozanov, 1975) among its subsystems (Note 4) (Dijkerman, 1974). The flows of matter and energy through the subsystems ("skeleton, solution, and plasma") of the soil system interfere with its pedogenesis (Hugget, 1976). This dynamic is altered over time (Rozanov, 1982); thus, its formation is an irreversible process (Yallon, 1975). According to Chatelin et al. (1982), this process explains the efforts, especially by pedologists, to understand the soil based on the General Systems Theory of Bertalanffy (Note 5). However, when applying this theory to the study of soil, it can no longer be analyzed through the action of an isolated factor. In systems with greater complexity, such as the soil, the elements are interconnected such that changes in one factor have immediate effects that change other factors (Rozanov, 1982). Thus, the soil system should be understood based on thermodynamics that consider non-equilibrium conditions and irreversible processes (Note 6) (Smeck et al., 1983). As a result, in 1988 in Brazil, the soil was described as a complex, living, and dynamic system that serves also to support plant development, which provides food and raw materials for human activity and it well-being (Almeida et al., 1988).

According to Phillips (1993), the functioning of soil should be studied by a systemic or holistic approach because their relationships are non-linear and dynamic. The soil system remains apart from the thermodynamic equilibrium and is characterized by minimal entropy production due to the predominance of ordering processes over dissipation processes over time (Addiscott, 1995). For at least six decades, the soil has been understood as an open system due to the flows of matter and energy that affect its functioning and evolution.

In this article, based on the evolution of human perception and the knowledge presented, it is believed that the soil is a system generated by the interactions among rock matrix, climate, and life prolonged over time; that it has variable thickness and occupies the largest portion of the mantle's surface (continental extension) on Earth; and that its functioning is determined by the interaction among its subsystems and affected by the flows that permeate it. However, the conception and nomenclature of the subsystems adopted by Nicolodi (2007) and in this article are different from those previously used by Hugget (1976), Mielniczuk et al. (2000), Vezzani (2001), Conceição (2002), and Schmitz (2003).

In the soil system, the solid portion (mineral and organic) determines the physical and chemical properties and traits of the soil as well as the life that exists in the soil, which are also affected by the liquid and gas portions. The reactions (exchanges of energy and matter) in the soil mainly occur due to animal (macro- and microorganisms) and vegetal (plant) life. In this article, the main interactions that occur in the soil system formed by plant, animal (Note 7), and human subsystems - and that are established among the soil system and the climate and life systems (Figure 1) are approached with the purpose of improving our understanding of soil system fertility perceived by plants according to presented by Nicolodi (2007). 


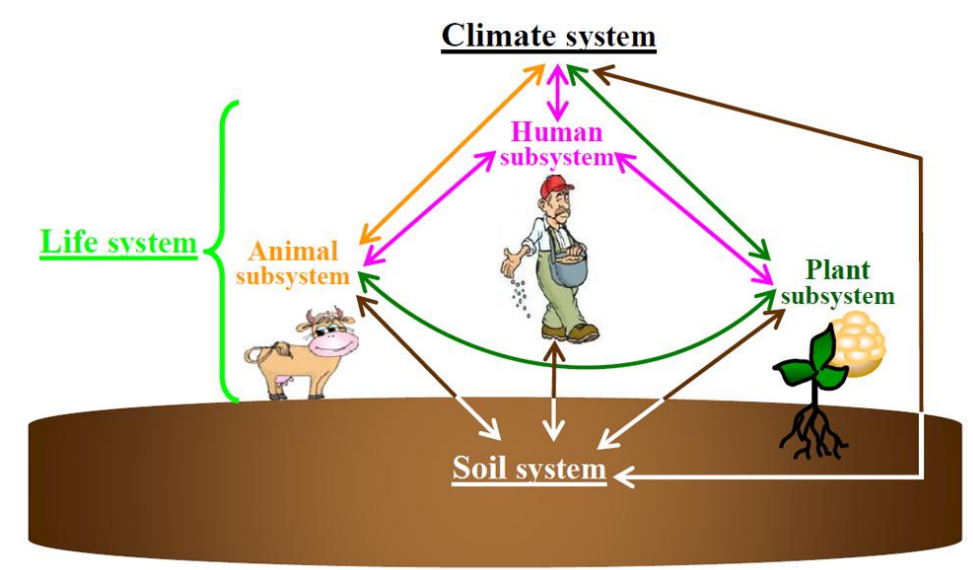

Figure 1. Main systems (climate and life) and subsystems (animal, plant, and human) that interact with the soil system (Nicolodi, 2007)

\subsection{Formation of the Soil System and Its Fertility}

The soil system indirectly originates from the interaction between regolith, or saprolite, (resulting from the climate acting on the rock matrix) and life, or it directly originates from the interaction among the rock matrix, climate, and life. According to Haussman (1950), in this process, regolith is sterile, depends on the presence of water and rocks decomposition to have fertility (to be fertile), and becomes suitable for the life of higher plants. The accumulation of these factors that distinguish soil from regolith depends on erosion and pedogenesis processes. Erosion leads to the acquisition of water and ends at the regolith phase. Pedogenesis submits the nutritional substances in the soil to geological (release of the mineral elements) and biological cycles (destruction and synthesis of organic substances). In the biological cycle, the development of fertility is determined by the succession of plant associations, landscape, and rock matrix in a given environment. Thus, for regolith to become fertile, i.e., turn into soil, qualitative changes promoted by the organic matter decomposition and humification process are necessary. Only after the action of life on regolith can it transform into soil, which is - by definition - a natural body characterized by a certain degree of fertility. This is a dynamic property resulting from multiple evolutionary processes linked to soil genesis that allows continuous access by plants to terrestrial growth factors such as water and nutritional elements and is the cause of their productivity, which resides specifically in the soil (Haussmann, 1950).

Over time, the intensity of the interactions among the rock matrix, climate, and life (plant, animal, and human) increases and accelerates the soil-formation process. The change in the intensity of the interactions is reflected in the degree of complexity and type of soil formed (Figure 2) and in the magnitude of its fertility (Nicolodi, 2007). According to the magnitude of fertility, a greater or lesser number of plant species develop and produce well in that soil, in absence of other limiting factors as weather, diseases, ecc.. According to Columella (42 AD), in perceiving that soils have different magnitudes of fertility, humans began to use this information to select soils for agriculture and livestock. 


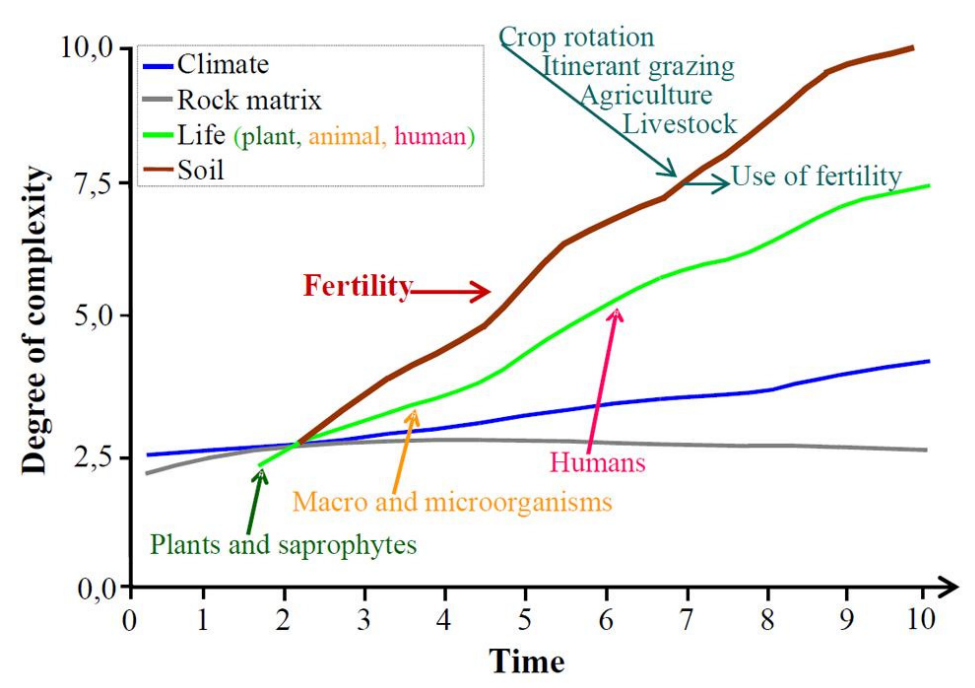

Figure 2. Formation of the soil and fertility (Nicolodi, 2007)

\subsection{Functioning and Functions of the Soil System}

Functioning refers to a maintained organizational pattern among the elements comprising and maintaining a system's "unit" to fulfill the functions of the system of interest and to their performance in fulfilling their functions relative to the main systems and subsystems with which they interact (Backlund, 2000). Soil system functioning is influenced by the actions and reactions of the systems and subsystems that they interact with. Thus, soil system functioning can be understood by identifying its main functions or the purposes of the systems and subsystems that interact with each other. Consequently, to understand soil's functioning, it is important to know the main elements, forces, and interactions that stimulate the processes that allow the soil system to fulfill its functions.

Soil system functioning is altered by initial conditions (soil type), the magnitude of the flows of matter and energy (species and cultivating intensity), and the interactions among its subsystems. The soil system self-organizes (Note 8) into different levels of order (Figure 3), which generates emergent properties that enable it to perform its functions according to its functioning (Vezzani, 2001; Vezzani \& Mielniczuk, 2009). Altering the soil's functioning also changes its evolutionary trajectory over time. As a result of functioning and the evolutionary trajectory of the soil being under constant formation, worse or better fertility emerges (Nicolodi, 2007).

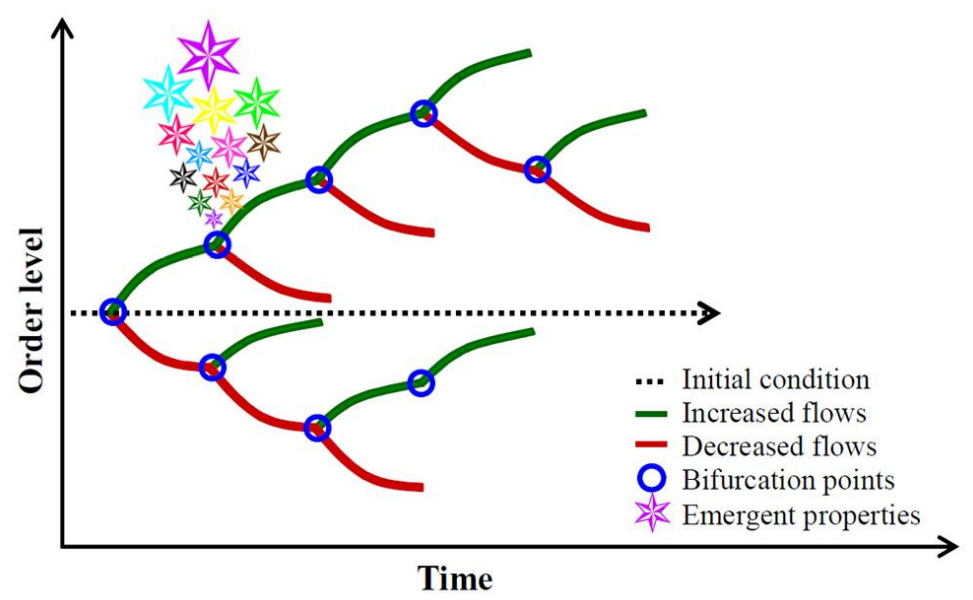

Figure 3. Auto-organization of the open systems described by Prigogine in his theory of dissipative structures (adapted from Prigogine, 1996) 
Soil functions are studied as a system resulting from the coexistence of multiple components (chemical, physical, and biological) that determine its fertility and profoundly influence the lives of plants (Bonciarelli, 1980). These plants and animals are the main sources of food for humans. Thus, since the 1990s, the functions of soil have been identified, especially in studies on soil quality — studying the suitability of a soil for a specific use (Gregorich, 2002) - although as the functions are fulfilled by soil rarely is cited in the scientific literature (Larson \& Pierce, 1991; Doran \& Parkin, 1994; Larson \& Pierce, 1994; Biswas \& Mukherjee, 1995; Brady \& Weil, 2002; Gregorich, 2002). The functions of the soil system that have been identified by these authors are as follows:

1. serve as a medium for plant growth:

1.1. anchor roots;

1.2. receive, retain, and release nutrients; and

1.3. receive, retain, and release water;

2. serve as habitat for soil organisms;

3. serve as a medium in human engineering construction;

4. regulate the flows of water, gases, and energy in the environment;

5. recycle raw materials and by-products;

6. respond to management and resist degradation;

7. support biological productivity;

8. promote health in humans, plants, and animals; and

9. sustain the lives of all creatures.

Based on reviewing the functions identified by these authors, we concluded that the functions should be "assigned" according to the understanding and need of each author to better understand the study's subject, in this case the soil. This attribution does not mean that the subject actually has these functions; rather, they are a useful device to better understand how other subjects interact with the subject of interest. Because soil system fertility is essential for the development and productivity of plants that are fundamental for feeding animals and humans, the soil functions exhibited following those "assigned" for the life system were separated for its plant (1), animal (2), and human (3) subsystems by Nicolodi (2007).

1. Essential functions of the soil system for the plant subsystem:

1.1. provide physical support for development and exchanges;

1.2. store and provide nutrients, water, and oxygen.

2. Essential functions of the soil system for the animal subsystem:

2.1. provide physical support for life above and below the soil;

2.2. serve as a medium for food production (fulfilling function 1).

3. Essential functions of the soil system for the human subsystem:

3.1. provide physical support for life above the soil (fulfilling function 2.1.);

3.2. serve as a medium for food production (fulfilling function 2.2.);

3.3. purify water (fulfilling function 1.2.);

3.4. buffer the temperature (fulfilling function 1.1.).

According to Nicolodi (2007), the main subsystems of the soil system are the structural subsystem and renewable subsystem. Due to our interest in the soil system conditions that allow for plant development and productivity, this article emphasizes the soil system functions towards the plant subsystem that are fulfilled by the essential processes that characterize those subsystems.

The structural subsystem represents the conditions that allow the roots of plants to grow and, at the same time, provide space and anchoring, which fulfills the function of providing physical support the plant subsystem for its development and exchanges. This function is fulfilled by the interaction among the soil particles (sand, silt, and clay), chemical (cation exchange capacity (CEC) and anion exchange capacity (AEC) or organic binders (exudates and humic substances), and the force (work) generated by root growth and the movement of animals and water during the soil aggregation process. The main indicators of the fulfillment of this soil function are as 
follows: root growth, water infiltration capacity, proportion of differently sized aggregates, and soil resistance to deformation.

The renewable subsystem represents the conditions that allow plants, through their roots, to absorb needed substances from the soil to form their structure, grow, and reproduce. The renewable subsystem thus meets the second function of the soil system: storing and making nutrients, water, and oxygen available for the plant subsystem. This function is fulfilled via the interactions between water, nutrients, oxygen, reactive surfaces (CEC and AEC), and fauna and microorganisms, via chemical processes and the electrical equilibrium between the solid-phase and the soil solution, and via other chemical-biological process that transform nutrients into forms available to plants (nutrient cycling stimulated by living organisms). The main indicators of fulfillment of this soil function are as follows: available water, the $\mathrm{CEC}$ and $\mathrm{AEC}$, the activity of specific biological communities, and the nutrient reserve and availability.

\subsection{Fertility: An Emergent Property of the Soil System}

The interaction among the subsystems of the soil system allow the emergence of numerous properties, including fertility (Nicolodi et al., 2004). Fertility is an emergent property of the soil system that provides the conditions necessary to sustain plant life; thus, fertility only manifests itself in the presence of plants (Nicolodi (2007; Figure 4). However, the magnitude of this fertility results from the interactions among the physical, chemical, and biological conditions in the processes that determine its functioning or fulfillment of its functions to (1) provide physical support for development and exchanges and (2) store and make nutrients, water, and oxygen available, i.e., fertility of different magnitudes emerges from the interactions among the structural and renewable subsystems. The magnitude is expressed in higher or lower plant productivity. Through the emergent property of fertility, the soil system fulfills its function of producing food for the animal and human subsystems.

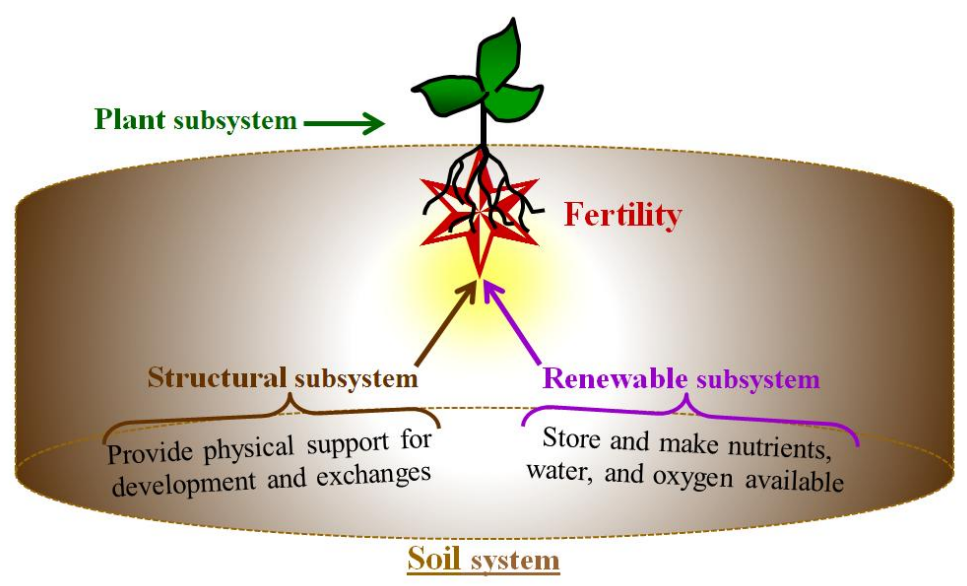

Figure 4. Fertility: an emergent property of the interactions between the structural and renewable subsystems of the soil system (Nicolodi, 2007)

Fertility is a term used in soil science to express the results of action of production factors on the yield (grains, dry matter, oil content, etc.) of a crop. It is not a soil constituent, and therefore it cannot be measured directly. It is a property projected by humans to better understand "the real thing" that exists in the soil, perceived and necessary for the productivity of plants. Thus, to evaluate fertility, other parameters are determined and the interpretation of the values quantified allows estimating the degree of fertility in a sample of soil. However, this evaluation is relative because the expression of fertility does not solely depend on soil factors but also on climate factors, mainly of the species cultivated (because the fertility can be adequate for one species but not another).

Currently, fertility is only evaluated using some indicators of the renewable subsystem. The first difference between this systemic notion and the mineralist notion is the direct contribution of the structural subsystem; the second difference is the action/participation of the water component of the renewable subsystem in the fertility (Nicolodi, 2007). These two differences are more important in tillage systems with less mobilization and with more biological diversity and addition of straws accumulation (residues of crops) that remain above the soil. In conventional tillage (CT), the soil is constantly turned (prepared with a plow and disc harrow) and the straw 
incorporated in the soil profile or burned, and the relationships constructed over time are destroyed; thus, not evaluating the structural subsystem does not significantly alter the evaluation of fertility because physical and biological conditions are very similar over time. In soils cultivated under no-tillage system (NTS), the relationships built in the soil over time are preserved and enriched by the diversity of species used in the crop rotation, and the chemical conditions, as well as the physical and biological conditions of the soil are modified and improved; thus, the structural subsystem affects the magnitude of fertility a great deal more. Because of this, the chemical evaluation based on the mineralist theory is most likely insufficient to express (determine or estimate) the fertility perceived by plants in soils cultivated under NTS (Nicolodi et al., 2014).

According to Nicolodi (2007), plant development and productivity (often described as the soil potential) are determined by the interaction between the plant subsystem (the particularities of the crop species) and the specific environment formed by the soil system fertility, life system, and topoclimate subsystem (Figure 5). Agriculture, which is characterized by cultivation of a specific environment by humans - a subsystem component of the system life - usually generates two products: one called productivity (food, grains/fibers/sugar/juice, dry matter, etc.; the primary product); and other called residue (roots and shoots; the secondary product) (Figure 5). The quantity and quality of the primary and secondary products depend on the interaction between the specific environment and the plant subsystem. Feedback or regeneration of the renewable and structural subsystems by plant residues and by adding fertilizers and amendments is, or should be, a consequence of this interaction. Thus, in this cycle, the fertility that will emerge at each cultivation of the soil system is constructed.

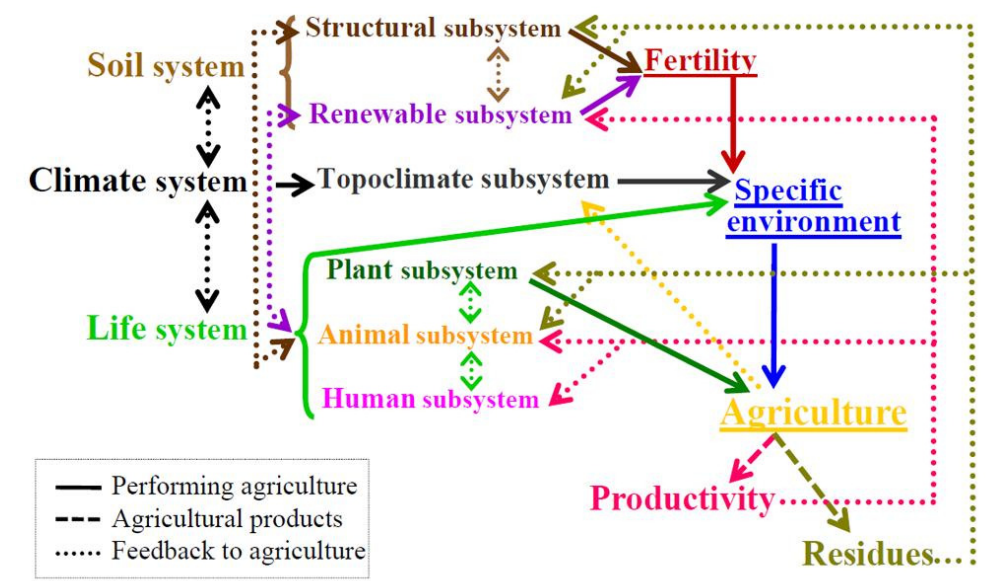

Figure 5. Importance of soil system fertility in generating agricultural products (Nicolodi, 2007)

Agricultural products mainly serve to feed and satisfy other needs of the human and animal subsystems. These products interfere in the subsystems and in the emergent properties that contribute in their generation. Because the primary product is the main source of revenue in agriculture to the human subsystem (usually the environment's steward), it is essential to know the main interactions (Figure 5) that influence the generation of fertility to stimulate its improvement and, consequently, increase crop productivity and improve or preserve the environment.

Agriculture does not exist without soil fertility and is only sustainable with high fertility. The indicators of fertility - and emergent the properties of soil functioning as a whole - are the same as those of the sustainability of agriculture. Columella stated in $42 \mathrm{AD}$ that fertility is the soil's ability to continuously renew itself through agricultural practices and abundant manuring. The "function" of the human subsystem is to stimulate this continuous renewal. Thus, agriculture should be sustainable, increasing productivity per area, avoiding unnecessary opening of new agricultural frontiers. The stimulus for renewing fertility should be made based on the diversification of crops and using adequate agricultural practices, not only for different crop species but also for the unlike topoclimate.

\section{General Considerations}

The reflection on the evolution of notion and the insufficiency of the mineralist concept indicate that the current 
time is ripe for an important change in our notion of fertility - composed by concept, evaluation, and practices recommended. Through historical review and the concern that often arises in relation to fertility, a new concept should be constructed soon. In the new concept, fertility can be considered an emergent property of the soil system (Nicolodi et al., 2004; D’Agostini, 2006; Schlindwein, 2006; D'Agostini, 2007; Denardin \& Kochhann, 2007; Nicolodi, 2007). The concept that fertility is an emergent property of the soil system that provides the conditions necessary to sustain plant life is more consistent with the meaning of the term "fertility" — the ability to produce abundantly — than the concept derived from the mineralist theory — the soil's ability to provide plants with nutrients in adequate quantities and proportions and to maintain the absence of elements toxic for their development - that is still in use.

A new notion should particularly be able to express the changes in the magnitude of the fertility perceived by plants in soils cultivated under NTS with diversification of species in the crop rotation. Based on the new concept, the evaluation of and the practices for increasing and maintaining fertility should be altered. The fertility of the soils cultivated under NTS will most likely not be evaluated only by chemical indicators, and these indicators will not necessarily be the same used under CT; if the same indicators were used, it is likely that the critical levels would be altered. Furthermore, it is necessary to evaluate the biological and physical conditions, i.e., the indicators of fertility should express the functioning of the soil system.

Fertility could be evaluated based on fulfilling the functions of the structural and renewable subsystems of the soil. Thus, soil not has fertility (is not fertile) if one or both subsystems do not fulfill their function for the plant subsystem. This is a rare situation, requiring that nothing grow in the soil. In contrast, a soil has fertility if the two subsystems fulfill their functions for plants. In this case, the fertility is low when the subsystems' functions are fulfilled with difficulty or is high when they are easily fulfilled. If the fertility is high, the soil system has the ability/potential to produce food in abundance.

The main practices for good functioning of the soil system, and consequently, to stimulate the emergence of fertility of a higher magnitude (Note 9), are as follows: stimulate good functioning of the structural and renewable subsystems via diversity of life (animal and vegetal); maintain high nutrient levels and the absence of toxic elements; and always maintain the soil cultivated with species with different root systems that add large quantities of high-quality organic material to the soil system and recirculate nutrients.

\section{Acknowledgements}

I am grateful to the graduate program in Soil Science at the UFRGS, to the Dipartimento di Energetica at the UnivPM, to the CNPq and CAPES for scholarships for the PhD program in Brazil and period in Italy; to Brazilian professors: Ibanor Anghinoni (UFRGS), Jacques Marrè (UFRGS), João Mielniczuk (UFRGS), Luiz Renato D'Agostini (UFSC), and Sandro Luiz Schlindwein (UFSC); to Italian professors: Franco Zucconi (UnivPM) and Davide Neri (UnivPM); to the researchers Otávio Antônio de Camargo (IAC) and José Eloir Denardin (EMBRAPA-Wheat) for their contributions and encouraging my discussions of fertility and the soil system.

\section{References}

Addiscott, T. M. (1995). Entropy and sustainability. European Journal of Soil Science, 46, 161-168. http://dx.doi.org/10.1111/j.1365-2389.1995.tb01823.x

Almeida, D. L., Santos, A. G., \& De-Polli, H. (1988). Manual on fertilization for Rio de Janeiro State, Brazil Manual de Adubação para o Estado do Rio de Janeiro (2nd ed.). Itaguaí, RJ, Brazil: Universidade Rural.

Backlund, A. (2000). The definition of system. Kybernetes, 29, 444-451. http://dx.doi.org/10.1108/03684920010322055

Bertalanffy, L. V. (1977). General systems theory - Teoria geral dos sistemas (3rd ed.) Petrópolis, RJ, Brazil: Vozes.

Biswas, T. D., \& Mukherjee, S. K. (1994). Textbook of Soil Science (2nd ed.). New Delhi, DEL, India: Tata Mcgraw-Hill.

Bonciarelli, F. (1980). Agronomy - Agronomia. Bologna, EM, Italia: Edagricole.

Brady, N. C., \& Weil, R. P. (2002). The nature and properties of soils. New Jersey, NJ, USA: Prentice Hall.

Camargo, T., \& Vageler, P. (1938). Soil in its modern conception - O solo na sua concepção moderna. In Instituto Agronômico do Estado (Ed.), The soils of São Paulo State II - Os solos do Estado de São Paulo II. Campinas, SP, Brazil: Imprensa Oficial do Estado. 
Capra, F. (1996). The web of life: A new scientific understanding of living systems - A teia da vida: uma nova compreensão cientifica dos sistemas vivos (trans.). São Paulo SP, Brazil: Cultrix.

Chatelin, Y., Richard, J. F., \& Leneuf, N. (1982). Modeles verbaux et transdisciplinarité dans l'étude de sols et dês paysages. Pedologie, 29, 51-63.

Chesworth, W. (1973). The residual systems of chemical weathering: a model for the chemical breakdown of silicate rocks at the surface of the earth. Journal of Soil Science, 10, 69-81. http://dx.doi.org/10.1111/j.1365-2389.1973.tb00742.x

Conceição, P. C. (2002). Evaluating land management systems considering evaluation of soil quality - Avaliação de sistemas de manejo visando à avaliação da qualidade do solo (Master's Dissertation). Universidade Federal de Santa Maria, Santa Maria, RS, Brazil.

Columella, L. G. M. (42 AD). The art of agriculture and book about threes - L'arte della'agricoltura e libro sugli alberi (reprint in 2003). Treviso, TV, Italia: Einaudi.

D’Agostini, L. R. (2007). Notion of soil fertility: (re)emerging systemic - Noção de fertilidade em solos: (re)emergindo sistêmica. Proceedings of the 31th Congresso Brasileiro de Ciência do Solo, Gramado, RS, Brazil: UFRGS and SBCS.

D'Agostini, L. R. (2006). Notion of system: (re)emerging fertile in soil, soil fertility (re)emerging systemic Noção de sistema: (re)emergindo fértil em solos, fertilidade do solo (re)emergindo sistêmica. Proceedings of the 6th Reunião Sul-Brasileira de Ciência do Solo, Passo Fundo, RS, Brazil: Embrapa Trigo and NRS/SBCS.

Denardin, J. E., \& Kochhann, R. A. (2007). Challenges for characterizing fertile soil in soil and water management and conservation - Desafios à caracterização de solo fértil em manejo e conservação do solo e da água. Revista Plantio Direto, 98, 16-21.

Denbigh, K. G. (1951). The thermodynamics of the steady state. New York, NY, USA: Wiley.

Dijerkman, J. C. (1974). Pedology as a science: the role of data theories in the study of natural soil systems. Geoderma, 11, 73-93. http://dx.doi.org/10.1016/0016-7061(74)90009-3

Dokuchaev, V. V. (1879). Mapping the Russian Soils. Saint Petersburg, SP, Russia: Imperial University of Saint Petersburg.

Doran, J. W., \& Parkin, T. B. (1994). Defining and assessing soil quality. In J. W. Doran et al. (Eds.) Defining soil for a sustainable environment (pp. 3-21). Madison, WI, USA: Soil Science Society of America. http://dx.doi.org/10.2136/sssaspecpub35.c7

Emmeche, C., Køppe, S., \& Stjernfelt, F. (1997). Explaining emergence: towards an ontology of levels. Journal for General Philosphy of Science, 28, 83-119. http://dx.doi.org/10.1023/A:1008216127933

Gregorich, E. G. (2002). Quality. In R. Lal (Ed.) Encyclopedia of Soil Science (pp. 1058-1061). New York, NY, USA: Marcel Dekker.

Haussmann, G. (1950). L'evoluzione del terreno e l'agricoltura: correlazione tra i processi pedogenetici, la fertilità, la tecnica e le rese delle colture agrarie. Torino, P, Italia: Einaudi.

Huggett, R. J., Yaalon, D. H., \& Chesworth, W. (1976). Conceptual models in pedogenesis: A discussion. Geoderma, 16, 261-266. http://dx.doi.org/10.1016/0016-7061(76)90027-6

Jenny, H. (1941). Factors of soil formation: a system of quantitative pedology. New York, NY, USA: McGraw-Hill.

Joffe, J. S. (1936). Pedology. New Jersey, NJ, USA: Rutgers University Press.

Kellogg, C. E. (1936). Development and significance of the great groups of the United States. Washington, WA, USA: Department of Agriculture.

Larson, W. E., \& Pierce, F. J. (1991). Conservation and enhancement of soil quality. Proceedings of the 2th Evaluation for Sustainable Land Management in the Developing World. Bangkok, Thailand: IBSRAM.

Larson, W. E., \& Pierce, F. J. (1994). The dynamics of quality as a measure of sustainable management. In J. W. Doran et al. (Eds.) Defining soil for a sustainable environment (pp. 37-51). Madison, WI, USA: Soil Science Society of America. 
Mielniczuk, J., Rheinheimer, D. S., \& Vezzani, F. M. (2000). Interactions between soil fertility and conservation - Interações fertilidade e conservação do solo. Proceedings of the 25th Reunião Brasileira de Fertilidade do Solo e Nutrição de Plantas, Santa Maria, RS, Brazil: UFSM and NRS/SBCS.

Nicolodi, M. (2007). Evolution of the notion of fertility and its perception as an emerging property of the soil system - Evolução da noção da fertilidade e sua percepção como uma propriedade emergente do sistema solo (Doctor's thesis). Universidade Federal do Rio Grande do Sul, Porto Alegre, RS, Brazil. Available in http://www.lume.ufrgs.br/handle/10183/8980

Nicolodi, M., Gianello, C., \& Anghinoni, I. (2004). Fertility: an emerging property of the soil system Fertilidade: uma propriedade emergente do sistema solo. Proceedings of the 5th Reunião Sul-Brasileira de Ciência do Solo, Florianópolis, SC, Brazil: UFSC and NRS/SBCS.

Nicolodi, M., Gianello, C., Anghinoni, A., Marré, J., \& Mielniczuk, J. (2014). The mineralist concept to express the soil fertility perceived by plants grown under no-tillage system. International Journal of Agricultural Science Research, 3, 187-195.

Odum, E. P. (1988). Base of ecology - Basi di ecologia. Padua, VN, Italia: Piccin Nuova Libraria.

Oliva, A. (1939). The agronomic theory of the fertility - La teoria agronomica della fertilità. Roma, LZ, Italia: Ramo Editoriali degli Agricoltori.

Patzel, N., Sticher, H., \& Karlen, D. L. (2000). Soil fertility: phenomenon and concept. Journal of Plant $\begin{array}{lllll}\text { Nutrition } \quad \text { and } & \text { Soil } & \text { Science, } & 163, & 129-142 .\end{array}$ http://dx.doi.org/10.1002/(SICI)1522-2624(200004)163:2<129::AID-JPLN129>3.0.CO;2

Phillips, J. D. (1993). Stability implications of state factor model of soils as a nonlinear dynamic system. Geoderma, 58, 1-15. http://dx.doi.org/10.1016/0016-7061(93)90082-V

Prigogine, I. (2003). The future is already determinate? - Il futuro é già determinato? (trans.) Roma, LZ, Italia: Di Renzo Editore.

Prigogine, I. (1996). The end of certainty - O fim das certezas (trans.). São Paulo, SP, Brazil: Editora Estadual Paulista.

Prigogine, I., \& Stengers, I. (1984). The new alliance: metamorphosis of science - A nova aliança: metamorfose da ciência (trans.). Brasília, DF, Brazil: Universidade de Brasília.

Prigogine, I., \& Stengers, I. (1992). Between time and eternity - Entre o tempo e a eternidade. São Paulo, SP, Brazil: Cia das Letras.

Rozanov, B. G. (1975). Genetical soil morphology. Moscow, Russia: Moscow University Press.

Rozanov, B. G. (1982). Methodological bases of modern soviet soil science and its future development. Pedologie, 29, 79-90.

Runge, E. C. A. (1973). Soil development sequences and energy models. Soil Science, 115, 183-193. http://dx.doi.org/10.1097/00010694-197303000-00003

Saltini, A. (1984). Storia delle scienze agrarie: l'agricoltura al tornante della scoperta dei microbi. Bologna, EM, Italia: Edagricole, Vol IV.

Schlindwein, S. L. (2006). The notion of soil fertility in its metamorphosis - A noção de fertilidade em solos e sua metáfora. Proceedings of the 6th Reunião Sul-Brasileira de Ciencia do Solo, Passo Fundo, RS, Brazil: Embrapa Trigo and NRS/SBCS.

Schmitz, J. A. K. (2003). Biological indicators of soil quality - Indicadores biológicos de qualidade do solo (Doctor's thesis). Universidade Federal do Rio Grande do Sul, Porto Alegre, RS, Brazil. Available in http://www.lume.ufrgs.br/handle/10183/3659

Smeck, N. E., Runge, E. C. A., \& Mackintosh, E. E. (1983). Dynamics and genetic modeling of soil systems. In L. P. Wilding et al. (Eds.) Pedogenesis and soil taxonomy (pp. 51-81). Amsterdan, Holland: Elsevier. http://dx.doi.org/10.1016/S0166-2481(08)70598-1

Vezzani, F. M. (2001). Quality of soil system under agricultural production - Qualidade do sistema solo na produção agrícola (Doctor's thesis). Universidade Federal do Rio Grande do Sul, Porto Alegre, RS, Brazil. Retrieved from http://www.lume.ufrgs.br/handle/10183/72665 
Vezzani, F. M., \& Mielniczuk, J. (2009). A vision on soil quality - Uma visão sobre qualidade do solo. Revista Brasileira de Ciência do Solo, 33, 743-755. http://dx.doi.org/10.1590/S0100-06832009000400001

Yallon, D. H. (1975). Conceptual models in pedogenesis: can soil-forming functions be solved? Geoderma, 14, 189-205. http://dx.doi.org/10.1016/0016-7061(75)90001-4

\section{Notes}

Note 1. A system is an integrated whole whose essential properties arise from the relationships among its parts. It is generated by a group of elements that interact in a model or organization pattern to obtain emergence, quality, or property inaccessible to the isolated parts (Bertallanffy, 1977; Backlund, 2000).

Note 2. Emergent properties are the properties of the whole that are not reducible to the sum of the effects of the isolated elements, are not present at the lower level, and cannot be explained or reduced to the elements that interact to generate it (Odum, 1988). The concept of emergence as "creation of new properties" was, according to Morgan (1923), coined by Lewes in 1875: something new that cannot be predicted from the constituent elements under the previous conditions. The product is not the mere sum of the separate elements. According to them, the difference between "resulting" and "emergent" is that the first can be predicted and the other cannot. Emergence seems to require given patterns of stability and reproducibility over time that are ensured by auto-organization (Emmeche et al., 1997).

Note 3. Thermodynamics is the field of physics that studies phenomena related to work, energy, heat, and entropy and the laws that govern the processes of energy conversion. Classical thermodynamics describes only those processes that exist before or after a restored equilibrium, i.e., the equilibrium states, but it is unable to specify the intermediate states through which the system passes. Thermodynamics of non-equilibrium was developed by Prigogine in the 1940s to improve our understanding of open systems and describes the intermediate or non-equilibrium states through which the system passes. The real processes consist of a succession of non-equilibrium states (spatial and temporal non-uniformity of properties, and local variations with time) (Prigogine \& Stengers, 1984).

Note 4 . The hierarchy among systems and subsystems is defined according to the object of study, considering that for something to be constituted into a system, it is necessary exist a common goal or specific function that is only reached or fulfilled by a particular set of processes. When several processes meet different goals or functions but all cooperate to reach a higher goal or meet a certain function, the latter is named a system, and its cooperators are subsystems (Backlund, 2000).

Note 5. In his General Systems Theory in 1945, Bertalanffy recognized that living organisms are open systems and that they cannot be described by classical thermodynamics (this fact was also recognized by Bogdanov that living systems are open systems that operate apart from equilibrium — in the Tectologia study, published between 1912 and 1917, little known at the time). Bertalanffy explained the differences between closed systems (exchange energy with the environment, tend to have maximum disorder, and remain in chemical and thermodynamic equilibrium) and open systems (exchange matter and energy with the environment, are maintained by continuous flows of these and by the construction and decomposition of components while living and far from equilibrium). This author coined the phrase "the whole is more than the sum of the parts," meaning that the constitutive traits of the system are not explainable from their isolated portions but from the knowledge of them and their relationships. Regarding the open system conception, the apparent contradiction between entropy (disorder) and evolution (growth of order) disappears. In the irreversible processes, the increased entropy is offset by imported entropy, which can be negative entropy (order). Thus, the internal entropy of the system may decrease and the life systems, in addition to preventing the increase in entropy, may develop in the direction of increasing order and organization (Bertalanffy, 1977).

Note 6. A process is irreversible when the system and all portions of its neighboring cannot return to the initial state. A system that undergoes an irreversible process is not impeded from returning to its initial state. However, if the system returns to the initial state, it is not possible to do the same with its neighboring.

Note 7. In this study, the components of the animal subsystem are considered to be all of the living beings that do not belong to the plant and human subsystems.

Note 8. Classical thermodynamics attributes the reversible character to the laws of nature; i.e., it radically negates the effects of time. This attribution was not accepted by Prigogine because "no conceptual scheme has established the equivalence between a plant that grows, flowers, and dies and a plant that revives, becomes young again, and returns to its seeds", and the past and future play different roles in most phenomena (Prigogine 
\& Stengers, 1992). In a 1947 article on non-equilibrium thermodynamics, Prigogine proposed that the auto-organization of open systems was associated with the removal of equilibrium. His first studies were contradictory due to two fundamental errors in classical physics: studying equilibrium conditions and ignoring the fact that many phenomena are non-linear. The greatest challenge of remedying these errors was one of the most extraordinary current cultural achievements fulfilled by Prigogine between 50 and 70 years. To demonstrate the first, he proposed non-equilibrium thermodynamics or irreversible processes, in which the effect of time was considered essential for characterizing the creativity and evolution of living beings. For the second, he used the sophisticated mathematics of the non-linear systems (Prigogine, 2003). With these two tools, he studied the evolution of open systems and described their auto-organization in his "Theory of Dissipative Structures." In this theory, the main features of life forms are linked to a coherent conceptual and mathematical framework and result in a change in perception from stability to instability, from disorder to order, from equilibrium to non-equilibrium, and from being to becoming. With this theory, Prigogine solved the puzzle of the coexistence of structure and change and order and dissipation. He went far beyond the conception of open systems to include the idea of points of instability in the new structures so that forms of order can emerge. He observed that near equilibrium, the system is stable; far from equilibrium, the system is unstable, and the irreversible processes are sources of coherence (Capra, 1996).

Note 9. The emergent properties are not predictable as specific values but as trends in behavior (these are better in the case of higher fertility or worse in the case of lower fertility).

\section{Copyrights}

Copyright for this article is retained by the author(s), with first publication rights granted to the journal.

This is an open-access article distributed under the terms and conditions of the Creative Commons Attribution license (http://creativecommons.org/licenses/by/3.0/). 